Check for updates

Edinburgh

Cite this as: $B M J 2022 ; 376: 05$ http://dx.doi.org/10.1136/bmj.05 Published: 4 January 2022

\title{
Covid-19: Fact check-how many patients in hospital are unvaccinated?
}

\section{Bryan Christie}

Intensive care units in the UK are filling up with patients with covid-19 who have not been fully vaccinated, a number of media reports have claimed over the past week.

It led to the prime minister, Boris Johnson, urging people to get vaccinated to reduce the pressure on hospitals. He said that he had been told by doctors that as many as $90 \%$ of patients with covid-19 in intensive care had not received a booster vaccination. ${ }^{1}$ Other media reports have suggested that $80-90 \%$ of patients in intensive care are unvaccinated. ${ }^{2}$

\section{Are these reports accurate?}

The Intensive Care National Audit and Research Centre (ICNARC), which has been monitoring activity throughout the pandemic, provides information on admissions to intensive care. ${ }^{3}$ Its latest report, published on 31 December, showed that the proportion of patients admitted to critical care in December 2021 with confirmed covid-19 who were unvaccinated was $61 \%$. This proportion had previously fallen from $75 \%$ in May 2021 to $47 \%$ in October 2021-consistent with the decreasing proportion of the general population who were unvaccinated-before rising again in December 2021.

The proportion of unvaccinated patients in intensive care varied by English region, with the highest rates recorded in London (66\%), the south west, and the north west. Being unvaccinated was classed as a person having no record of receiving any vaccination or having had a first dose administered within 14 days of receiving a positive covid test, and only $1.9 \%$ of the "unvaccinated" group had received a first dose within that period.

The $61 \%$ figure is lower than the $80-90 \%$ reported at some hospitals. But the latest ICNARC data span only to 15 December, and the proportion of patients in intensive care who are unvaccinated may have increased as the omicron variant spread in December. Some hospitals will also have been more badly affected than others.

\section{What about admissions outside intensive care?}

The UK Health Security Agency (UKHSA) has recently started to report hospital admissions-not just those to intensive care-alongside vaccination status. The latest figures show that in the week to 29 December 2021 a total of 815 people with confirmed omicron infection were admitted from an emergency department to hospitals in England. Of these, 74\% had not had three doses of vaccine-including $25 \%$ (206) who were unvaccinated, 6\% (49) who had received one dose, and $43 \%$ (352) who had received two doses. Twenty three percent (189) had received a booster dose, and the remainder were unknown or had had their first dose less than three weeks ago. 4

Further analysis by the agency has concluded that unvaccinated adults are as much as eight times more likely to be admitted to hospital than those who have been vaccinated and that booster doses are $88 \%$ effective at preventing hospital admission. ${ }^{4}$

A separate report published by the UKHSA showed that, although unvaccinated individuals made up only a small proportion of the overall population, they accounted for $27 \%$ of those with a confirmed case of omicron admitted to hospital in England and for $39 \%$ in London. ${ }^{5}$

The Office for National Statistics' latest report on deaths from covid-19 covering the period from January to October last year in England found that the age adjusted rate of death was $96 \%$ lower in people who had received a second dose of vaccine than in those who were unvaccinated. ${ }^{6}$

\section{Do we need better data in the UK?}

The UK has a wealth of data on the positive impact of vaccination, but the figures are held in different places and piecing them together is not simple. This has led to calls for the UK to follow the lead of the US Centers for Disease Control and Prevention, which publishes daily information on the progress of the pandemic, including infection rates by vaccination status. $^{7}$

\section{Correction: On 13 January 2022 we amended an incorrect link in reference}

6.

UK's Johnson warns of hospital risk for unvaccinated. Reuters. 29 Dec 2021 https://www.reuters.com/world/uk/uks-johnson-says-people-without-covidboosters-ending-up-hospital-2021-12-29/

2 Weaver M. "Help us to help you": doctors in England make pleas to unvaccinated. Guardian 2021 Dec 22. https://www.theguardian.com/society/2021/dec/22/help-us-to-help-you-doctors-in-england-make-pleas-tounvaccinated

3 Intensive Care National Audit and Research Centre. https://www.icnarc.org/Our-Audit/Audits/Cmp/Reports

4 UK Health Security Agency. SARS-CoV-2 variants of concern and variants under investigation in England. 31 Dec 2021. https://assets.publishing.service.gov.uk/government/uploads/system/uploads/attachment_data/file/1044481/Technical-Briefing-31-Dec-2021-Omicron_severity_update.pdf

UK Health Security Agency. Omicron daily overview: 31 December 2021 summary. 31 Dec 2021. https://assets.publishing.service.gov.uk/government/uploads/system/uploads/attachment_data/file/1044522/20211231_OS_Daily_Omicron_Overview.pdf

6 Office for National Statistics. Deaths involving COVID-19 by vaccination status, England: deaths occurring between 1 January and 31 October 2021 20 Dec 2021. https://www.ons.gov.uk/peoplepopulationandcommunity/birthsdeathsandmarriages/deaths/bulletins/deathsinvolvingcovid19byvaccinationstatusengland/deathsoccurringbetween1januaryand31october2021

7 Centers for Disease Control and Prevention. Covid data tracker. https://covid.cdc.gov/covid-data-tracker/\#rates-by-vaccine-status 
This article is made freely available for personal use in accordance with BMJ's website terms and conditions for the duration of the covid-19 pandemic or until otherwise determined by BMJ. You may download and print the article for any lawful, non-commercial purpose (including text and data mining) provided that all copyright notices and trade marks are retained. 